\title{
The Role and Strategy of Diversified "Artisan" Talents in Contemporary Ceramic Painting
}

\author{
Long Zhou \\ Jingdezhen Ceramic Institute \\ Jingdezhen, China 333403
}

\author{
Lingxia Zhang \\ Jiangxi Ceramic Fine Art Profession Academe \\ Jingdezhen, China 333001
}

\begin{abstract}
Talents of contemporary ceramic painting have entered an "Artisan" era, most of talents consist of professional, crossover and academic talents, which are professional, open, knowledgeable and inclusive. Artisan talents play significant roles in enhancing the overall strength of ceramic painting, innovation, reform and manifestation of individual characteristics. In order to further develop and optimize the diversified artisan talents, it still needs to take measures in channel, flow, complexity and subdivision in order for improvement.
\end{abstract}

Keywords-contemporary ceramic painting; artisan; pattern; diversified talents; craftsmanship

\section{INTRODUCTION}

In recent years, artisan talents have become new development orientation for talents of contemporary ceramic painting, which is an inevitable result of the post industrial era and also a response to the Artisan spirit advocated in the country. After China's reform and opening up, talents of ceramic painting have been in a great increase, though they come from different fields through diverse ways and have all kinds of social status and educational background, yet most of them have selected the way where art and process are focused on in the past years, and a new trend of Artisan talents has come into being, which forms talents of diversified ceramic painting and becomes key factors to drive the healthy development of ceramic painting.

\section{FORMATION AND CHARACTERISTICS OF ARTISAN TALENTS IN CERAMIC PAINTING}

Differing from general workers who take work result as purpose which is separated from the work activity and belongs to self-forced labor, artisans don't take the work as a mean to achieve the purpose instead, they seek for what the value of life is through working in a material world.

Generally outstanding artisan activities are focused on what the things are and impersonal operational procedures, holding a spirit of artisan including sharing experiments, experience skills and collective cooperation and taking the work as an art, which is a realm of freedom. Seen from some perspective, artisans are excellent representatives of craftsmen. Starting from handicraftsmen in Pre-Qin Dynasty, there were a

*Fund Project: 2016 Humanity \& Social Science Research Project in Colleges of Jiangxi Province (YS162013). great number of artisans among handicraftsmen in process and fine art activities such as ceramic painting in ancient times

Analyzing the development history of ceramic painting longitudinally in ancient China, artisans were dominators among talents of the ceramic painting and key strength to drive the ceramic painting. The development of ceramic painting mainly took place in feudal society when under the hierarchy of "scholar, farmer, craftsman and merchant", practices were looked down, and experimental and technical skills were regarded unimaginative and non-elegant. Acting as craftsmen, talents of ceramic painting in the family workshops which was based on the master-- apprentice relations were continued through the heritage of experience generation by generation, so the talents were simple.

The single craftsman talents of ceramic painting started to change till the late Qing Dynasty and the period of Republic of China. With the bankruptcy of royal kilns, painters started to think of their value to continue, and the contemporary ceramic painting began to awaken. From then on, Accompanied with the participation of scholars who were gentries from noble families, some ceramic painting started to be separated from purposes and became relevantly independent aesthetic activity, thus it went on a divided way to fine art and process.

After foundation of new China, the ceramic painting entered the contemporary period, and the talented people were greatly adjusted on the basis of existing foundation of that time, and the status of ceramic painters was highly improved. Marx affirmed in his works Umrisse $\mathrm{zu}$ einer Kritik der Nationaloeknomie the important roles of artisans as harmonious individuals in social relations during the manufacturing of goods. Marx in his works Critique of the Gotha Programme even raised: Communism will carry forward artisan activities once again. It stressed that artisans' creative activities could help laborers develop roundly, truly achieving the dignity in labor. Influenced by the ideology of respect and encouraging artisans, the artisans' activities were socialized. Outstanding talented people in ceramic painting were gradually transferred to research institutes, schools and aesthetics research offices of ceramic plants and so on, which placed a foundation for the diversified talents in the future.

After the 1980s, with the development of market economy, talented people in ceramic painting started to change dramatically, driven by the market, talented people in ceramic painting were not limited to public ownership institutions. 
Especially since the late 1990 s, more and more talented people in ceramic painting had left the public ownership institutions, instead, they went to work in private enterprises or developed as individuals, which formed a basic situation with diversified talents, where public institutions, private enterprise and individual workshops are longitudinal and scientific research, education and industries are horizontal.

Mar 5, 2016, Prime Minister Li Keqiang raised the word "spirit of craftsman" in the government work report, on the background of upgrade of Made in China and consumption, to cultivate artisan talents is valued again. Facing the situation of spirit of craftsman advocated across the country, new requires are raised to talented people in ceramic painting, and the artisan talents have become a new trend for the development of talented people in ceramic painting. In contemporary ceramic painting, the artisan talents are workers of ceramic painting art, who have spirits of craftsmen. The new view integrates characteristics of talented people in art aesthetics and technical skills in ceramic painting, and they are new talents who own art and skills, on the one hand, they have higher artistic attainments and cultivation, on the other hand, they have higher technical level.

Seen from the status quo, the artisan talents of contemporary ceramic painting are diversified, mainly including: First, professional talents, they are distributed at private enterprises, public institutions or startup businesses, specializing in ceramic painting. They are employees who graduated from colleges and have mastered higher skills in ceramic painting and technical workers who learned from teachers according to traditional mode, self taught or further studied for improvement; Second, crossover talents, namely they are talents who transfer from other art field to short or long term ceramic painting. The talents consist of oil painters and traditional Chinese artists who have entered the ceramic painting field in a large amount in recent years, with higher art quality, after studying knowledge of ceramic materials and process, they have well mastered the skills of ceramic painting; Third, academic talents. They are mostly teachers of ceramic art education in colleges, who are comprehensive talents integrating painting, study and research and connect ceramic painting creation with teaching and scientific research and bear the responsibilities of cultivating talents.

Contemporary diversified artisan talents in ceramics have distinct characteristics, mainly including: First, open. Talents of ceramic painting are not limited by regions or employers, who are free to flow such as a great number of Jingdezhen Drifters at Jingdezhen Town. Second, knowledge. The proportion of talents of ceramic painting with high degrees is increasing day by day, which is closely related to the enrollment expansion in colleges of ceramics; Third, inclusive. Talents who have diverse art styles and skills get along well with each other, and all are inclusive; Fourth, multilevel. Actually talents of ceramic painting are not equal, who are classified as per title, degree and so on.

\section{ROLES OF DIVERSIFIED ARTISAN TALENTS IN THE DEVELOPMENT OF CONTEMPORARY CERAMIC PAINTING}

Talents, the most active factor, play a crucial role in the development of contemporary ceramic painting. Contemporary talents of ceramic painting have changed to fusion from division of artists and artisans in the past and the diversified artisan development is encouraged, which can not only do good to fully playing the core role of talents in promoting the development of ceramic painting and make them be foundation for the continuous prosperity of contemporary ceramic painting, but also bring significant influence on the inheritance and innovation of contemporary ceramic painting art styles and technical skills.

First, borrow and learn to enhance the overall strength. Seen from the overall development environment, the status of contemporary ceramic painting in the art field is improved constantly, yet obviously the separation from artists and craftsmen will be bad for the overall development and improvement of ceramic painting. Divided talents may cause ceramic painting artists pay less attentions to improving or even looking down skills, besides, the workers of ceramic painting are excessively limited to technical skills and ignore the improvement of artistic accomplishment, that is, who are in a binary opposite position of "aesthetics - freedom" and "technical- No Freedom". Actually the cultivation of "artisan" talents is to achieve the dialectical unity of the two from the opposing state, borrow and learn from each other. The overall strength of ceramic painting will be enhanced during the fusion and collision, and more outstanding works will be provided to attract the eyeballs of fine art field and become a member of them.

Second, market competition and innovation for development. Facing the traditional and single situation where "art" and "artisan" are divided, there is almost no competition between talents of ceramic painting, whether artists or craftsmen both are in a linear development, who rank as per qualification and seniority, having no enthusiasm to innovation for development. However, with the fusion of artists and craftsmen, facing a situation of diversified artisan talents, traditional talents have to not only face the possible replacement by professional talents but also meet challenges of crossover and academic talents, its dominant advantages in the market has been weakened, and the market-oriented arts and crafts development have enter an era of multiple competition. Facing the competition, contemporary talents of ceramic painting take active or passive innovation in art and process and strive to compete in the market through renovation, thus a drive for the innovation and development of contemporary ceramic painting has come into being.

Finally, highlight features and individual spirits. Artisan talents have promoted contemporary ceramic painting to form diversified culture, while driving the innovation of contemporary ceramic painting. Artist talents differ from the directions of innovation and reforms, for example, professional artisan talents generally take progressive method, that is, innovation on the basis of traditional foundation; yet academic artisan talents pay more attentions to science and concept; crossover artisan talents generally are free, as a result, the 
ceramic painting has formed diverse technique, art and cultures, and individual spirits are fully demonstrated, which make the development of contemporary ceramic painting more distinctive and dynamic.

\section{DEVElopMENT STRATEGIES OF DIVERSIFIED ARTISAN TALENTS IN CONTEMPORARY CERAMIC PAINTING}

Actually the artisan talents have become a general trend for the development of talents of contemporary ceramic painting, yet it is still not mature in development, and there are still some problems existing, and the structure and vitality of talents needs to be further optimized. Therefore, in order to make the development of artisan talents of contemporary ceramic painting more reasonable for development and exert the roles of talents and further promote the healthy development of contemporary ceramic painting, the ceramic painting field, authorities and departments should take effective development strategy so as to make the diversified artist talents play a more active role in the contemporary ceramic painting.

First, build more channels for up-going and protect and foster the diversified artisan talents for contemporary ceramic painting. Talents of contemporary ceramic painting graded from low and high in title, with honors as masters from provincial level and state level, which are like millions and millions of soldiers traveling through a single wooden bridge. The formation of artisan talents has laid a foundation to break through the traditional practice, the whole society should work together to build diversified channels for the up-going of talents, breaking the concepts of title first and only, instead, we should depend on multiple standards such as artistic level, technical grade, social contribution and so on to evaluate talents, and avoid to blunt the enthusiasm of talents due to the lack of development prospect so as to protect and achieve the development of diversified talents.

Second, optimize the talent structure and promote the artisan talents of contemporary ceramic painting to flow. The artisan talents of contemporary ceramic painting are fixed to a large extent, though seen from the overall situation, all kinds of talents can flow freely yet there are still prejudice and even hostility existing between them, potentially the artisan talent structure becomes a barrier for diversity to some degree, which obviously will do bad to the development of ceramic painting. Therefore, to promote the talent flow is a key factor to optimize the talent structure, all kinds of artisan talents should abandon the sectarianism, flowing freely through communications so as to improve contacts between them and form a cooperative relation but not opposition.

Third, aim at artisans talents and cultivate compound talents with artisan spirits. With the rapid development of contemporary artisan talents of ceramic painting, characteristics of compound talents are becoming more and more prominent, and new requirements are raised for the cultivation of fostering reserve talents of ceramic painting. Therefore, schools, institutions, enterprises and individuals which are responsible for the cultivation of contemporary talents of ceramic painting should take the mission of improving the quality of talents and stress the cultivation of spirits of craftsmen while strengthening students' capabilities of skills, painting quality and knowledge. And the spirits of craftsmen shall be taken as a link to integrate multiple fields and cultivate compound talents of ceramic painting.

Finally, based on market segments, we shall continue to broaden the artisan talents. The formation of contemporary diversified talents depends on the market demand to a large extent and the increased market demands for ceramic painting works which are exquisite in art and technique. Going with the in-depth development and upgrade and renewal of consumer market, in order to meet the needs of different groups, the arts and crafts market will be subdivided. In the future, the market segmentation will be further developed, which provides important external factors for expanding the contemporary artisan talents of ceramic talents. Guided by the current transformation and upgrade of consumption structure, talents will be subdivided as well so as to meet the market demand, and the artisan talents will be further broadened to guarantee the healthy and sustainable development and arts and crafts consumption.

\section{CONCLUSION}

Currently, a contemporary diversified talent pattern of ceramic painting has been formed in the country, though a great number of talents of ceramic painting differ in professional level, styles and comprehensive abilities, yet they share the same creative pursuit with artistic level and technical skills integrated. As a result, there are more and more artisan talents which play a crucial role in driving and promoting the development and booming of contemporary ceramic painting in the country. With the in-depth development of reform and opening up in the country, contemporary artisan talents of ceramic painting will continue and expand, with the full efforts made by all social fields, all kinds of strategies will be adopted to optimize and improve the diversified artisan talents structure and it will be certain to play an active role in booming the ceramic painting in the future.

\section{REFERENCES}

[1] Yu Ci, Jiang Yueguang, Jiang Yuanping, Discussion on Crossover Ceramic Painting of Contemporary Artists [J]. Chinese Ceramics, 2013, 49 (04): 73-75

[2] Yu Changmin, Discussion on Art Phenomena of Jingdezhen Drifters [J]. Ceramics Science \& Art, 2014 (03) : 16- 19.

[3] Cai Rui, Artistic Characteristics of Academism Ceramic Art Creators [J]. Modern Decoration (Theory), 2015 (12) : 141

[4] Zhang Zhentao, Discussion on Artisans [J]. Studies on Culture \& Art, 2008 (01): 121- 127 . 